Running head: EFFICACY BELIEFS AND LEADERSHIP

Running head: EFFICACY BELIEFS AND LEADERSHIP

\title{
The Impact of Group Efficacy Beliefs and Transformational Leadership on Followers' Self-efficacy: A Multilevel-Longitudinal Study
}

\author{
Marisa Salanova \\ ORCID: http://orcid.org/0000-0001-7873-7078 \\ WANT Research Team. Universitat Jaume I, Spain
}

Alma M. Rodríguez-Sánchez

IDEA Research Team. Universitat Jaume I, Spain

Karina Nielsen

ORCID https://orcid.org/0000-0001-9685-9570

Management School, Sheffield University, UK

Author note

This study was supported by a grant from Ministerio de Economía y Competitividad. Gobierno de España (\#PSI2015-64933-R) and Universitat Jaume I (UJI-B2017-81).

Correspondence concerning this article should be addressed to Professor Marisa Salanova, Department of Social Psychology, Universitat Jaume I, Av. Sos Baynat, s/n. 12071 Castellón (Spain). Tel. +34 964 729583. Fax +34 964 729262. E-mail: salanova@uji.es. 


\begin{abstract}
Using Social Cognitive Theory as our theoretical framework, we analyse how beliefs about group efficacy among team members, together with transformational leadership are two group-level constructs (aggregated members' shared beliefs), which predicts individual members self-efficacy over time. We conducted a three-wave longitudinal study with 456 participants that were randomly distributed in 112 groups working in three simulated creative collective tasks. We computed random coefficient models in a lagged-effects design. Findings were as expected and group efficacy beliefs and grouplevel transformational leadership were relevant cross-level predictors of individual selfefficacy over time (even after controlling for baseline levels of individual self-efficacy). Results suggested that these group-level factors are relevant cross-level constructs that explain how individual self-efficacy among group members is developed over time.
\end{abstract}

Key words: Group efficacy beliefs, transformational leadership, individual self-efficacy, multilevel analysis, longitudinal design. 


\section{The Impact of Group Efficacy Beliefs and Transformational Leadership on} Followers' Self-efficacy: A Multilevel-Longitudinal Study

For decades, psychological research showed about the positive benefits of selfefficacy on performance (Lisbona et al., 2018; Peterson et al., 2011; Schneider \& Preckel, 2017; Stajkovic, Lee, \& Nyberg, 2009; Talsma, Schüz, \& Norris, 2019) and well-being (Buric \& Macuka, 2018; Guarnaccia, et al., 2018; Nielsen \& Munir, 2009; Salanova, Llorens, \& Schaufeli, 2011), to name just a few. Research is clear that selfefficacy helps people (employees, students, etc.) to manage their task/job demands and motivates them to be more engaged in their jobs, leading to better performance and feelings of positive subjective well-being.

However, most of this self-efficacy literature has focused almost exclusively on one level of analysis, i.e. self-efficacy or collective efficacy beliefs and their consequences (i.e., performance and/or well-being). Less is known about multilevel drivers of self-efficacy. For example, is there a contagion effect such that when the group feels efficacious, the individual members can feel self-efficacious as well? Or does a transformational leader make us believe in our ability to successfully manage specific challenges in our activity?

Given that groups have become the basic unit of work organization and work accomplishment (Hirschfeld \& Bernerth, 2008), the answer to these questions is necessary in order to know how to build future self-efficacy by means of group features such as collective efficacy and leadership. Thus, in the current study, we will test whether group collective efficacy beliefs and transformational leadership (two groupbased psychosocial constructs) can explain future levels of self-efficacy, above and beyond previous levels of group members' self-efficacy. We intend to increase the 
understanding of the processes involved in the complex (i.e., group, multilevel) predictors of individual self-efficacy over time. Moreover, we investigate how grouplevel shared perceptions of transformational leadership can be cross-level antecedents of individual self-efficacy over time. Therefore, we perform a multilevel and longitudinal study in order to understand the cross-level dynamics of these psychological experiences over time.

\section{Group efficacy beliefs and self-efficacy}

According to Bandura (1997), collective efficacy beliefs are "shared beliefs in group capacities to organize and execute the courses of action required to produce given attainments" (p. 447). Research carried out in organizations demonstrates that when individuals cooperate, they may share convictions and attitudes thus showing comparable persuasive and personal conduct standards (George, 1990, 1996) furthermore, encountering a common group emotional tone (Barsade, 2002; Bartel \& Saavedra, 2000). A developing group of research accentuates the effect (e.g. affective, motivational and, behavioural effects) of perceived collective efficacy on group processes (Alavi, \& McCormick, 2018; Gully, Incalcaterra, Joshi, \& Beaubien, 2002; Nielsen \& Daniels, 2012; Salanova, et al., 2003; Salanova, Llorens, \& Schaufeli, 2011; Stajkovic, Lee, \& Nyberg, 2009).

Moreover, Social Cognitive Theory (SCT) identifies four predictors of efficacy beliefs: enactive mastery experiences, vicarious experiences, social influence through verbal persuasion, and (positive/negative) affective states. According to Bandura, (2001, 2012), research indicates that performing a challenging task (i.e. mastery experience) can improve people's self-efficacy beliefs. In addition, self-efficacy is affected by vicarious learning, which takes place when people observe efficacious people (working individually or in teams) performing a similar task. According to Bandura, the more 
noteworthy the apparent similitude between the role model and the objective individual, the more prominent the model's effect on the individual's self-efficacy will be. Verbal influence through social persuasion, for example, by positive leaders, is another mechanism to improve self-efficacy. Finally, the fourth major source of self-efficacy consists of (positive/negative) affects. For example, when individuals feel eager or fulfilled, they are likely to trust that they are useful and efficacious as well.

According to the SCT, and at the collective level, we could expect that when a group shares efficacy beliefs about good group performance (enactive mastery and vicarious experiences), they could feel more efficacious as individuals due to psychological mechanisms such as positive emotional contagion, defined by Hatfield, Cacioppo, and Rapson (1994, p.5) as the "tendency to automatically mimic and synchronize facial expressions, vocalizations, postures and movements with those of another person and, consequently, to converge emotionally". This emotional contagion has been applied to many contexts, including organizations and, specifically, research on teams and leadership processes (Tee, 2015; Torrente, Salanova \& Llorens, 2013). We could expect that when group members feel efficacious, they also potentially exchange other positive emotions, such as joy, satisfaction, or pride in a job well done. According to Bandura, emotional expression is a valuable source of self-efficacy (the fourth source of self-efficacy). We propose that collective expressions of positive emotions about work well done could lead members to feel other positive emotions and, in turn, increase their individual self-efficacy over time.

It is important to understand whether collective beliefs of efficacy have crossed effects on individual self-efficacy over time and previous research has not studied these effects. A collective shared perception that a group feels efficacious in obtaining a specific goal could encourage each individual's beliefs that s/he can achieve 
the goal/s as well ("If my group can, so can I"). We expect that individuals who work in a group where members believe that they have the capabilities to achieve group goals may, over time, come to believe that they can achieve their individual goals as well. Thus, we expect to find a positive relationship between collective efficacy and individual self-efficacy over time.

Hypothesis 1: Group-level collective efficacy at T2 has a significant cross-level effect on individual self-efficacy at T3, above and beyond previous levels of selfefficacy at $\mathrm{T} 2$ and at $\mathrm{T} 1$.

\section{Shared transformational leadership perceptions and individual self-efficacy}

Transformational leaders develop close inter-relationships with collaborators minimizing the distance between leaders and collaborators, in spite of "their ability", and by individualized beliefs about members' needs and abilities (Bass, 1990). This relationship is based on trust between leaders and followers, transparent communication, and empathy between leaders and followers, thus potentially enhancing their individual efficacy beliefs through vicarious experiences and social persuasion (Walumbwa et al., 2011). In this regard, leaders' behaviours influence cognitions, emotions, and behaviours of followers. Leggod, Thomas and Sacramento (2016) recently showed that leaders' trustworthy behaviour influenced organizational trust via trustworthiness perceptions and followers' trust in their leaders. Research suggests that a positive leadership style may exert its influence on followers through other psychological mechanisms such as self-efficacy (Stetz, Stetz, \& Bliese, 2006). For example, Pillai and Williams (2004) found that transformational leadership was related to followers' self-efficacy in a sample of American fire service organizations. Salanova, Lorente, Chambel and Martínez (2011) found a direct path between transformational leaders and nurses' self-efficacy in 280 dyads (supervisors and nurses). Moreover, in a 
sample of nurses, Afsar and Masood (2018) demonstrated that creative nurses'selfefficacy is a psychological mechanism (in interaction with others such as trust in supervisor and uncertainty avoidance) that explained how transformations leadership, influenced on nurse's innovative job behaviour.

According to SCT, enactive mastery is an important antecedent of self-efficacy (Bandura, 1997), which depends on previous success on similar tasks. Other important antecedents of self-efficacy may include social persuasion, vicarious experiences, and positive affect, all of these strategies may be employed by positive leaders (Sivanathan, Arnold, Turner, \& Barling, 2004). In this regard, Podsakoff, MacKenzie, Moorman, and Fetter (1990) showed that transformational leaders influence collaborators' self-efficacy because leaders are modelling the right behaviours and followers identify with leaders through observational learning. Transformational leaders may improve followers' selfefficacy when they express high expectations that followers can successfully overcome difficulties (the Pygmalion effect, Eden, 1990). Transformational leaders also affect their collaborators' sense of efficacy through intellectual stimulation when they encourage followers to develop solutions to the challenges they face, rather than suggesting solutions themselves, thus encouraging followers to find better ways of doing things (Sivanathan et al., 2004).

A group's perception that they have a transformational leader who encourages trust, empathy, and authenticity (social persuasion) may contribute to enhancing the individual efficacy beliefs of the followers. Research has found that positive leadership behaviours (i.e., transformational, authentic, ethic...) predicted collaborators' selfefficacy (Afsar, \& Masood, 2018; Dvir, Eden, Avolio, \& Shamir, 2002; Kark, Shamir, \& Chen, 2003; Nielsen \& Munir, 2009; Wallumbwa, et al., 2011). In his review, Tee (2015) also showed that emotional contagion processes are developed from bottom-up 
through intra-individual and between-individual factors to top-down from leaders to followers affecting to different organizational outcomes (Barsade \& Knight, 2015).

Furthermore, based on emotional contagion as an explanatory mechanism and the fourth source of individual self-efficacy, research has shown the effect of how the moods of leaders influence on group positive affect. Chi, Chung, and Tsai (2011) showed that these positive leader emotions influence the group's positive affect. Also, group positive affect is associated with job performance and, in turn, on individual selfefficacy (Seong \& Cho, 2014; Zhang, et al., 2017).

Research on the way transformational leaders influence group members' selfefficacy has mainly used a single level of analysis, i.e. the individual level. Thus, individual perceptions of leaders were linked to individual self-efficacy. For example, Liu, Siu and Shi (2010) showed that transformational leaders influence individual followers' self-efficacy and, in turn, employee well-being. According to Yammarino, Dionne, Chun, and Dansereau, (2005), previous research on transformational leadership has neglected the consideration of transformational leadership as a group/organizational factor as well. For example, how a leader relates to a group of followers or shared perceptions among the group members (i.e. within-group agreement) about how transformational their leader is. As far as we know, no multilevel studies have examined how shared perceptions of group members about transformational leadership (group level of analysis) are linked to individual self-efficacy (individual level of analysis) across levels. It is important to note that, in the study by Wallumbwa et al, (2011), an aggregated measure of ethical leadership was linked to followers' self-efficacy. In our study, we take a step forward by including not only aggregated leadership, but also collective efficacy, as multilevel predictors of individual self-efficacy, using a longitudinal design. In their meta-analysis on transformational leadership, Wang, Oh, 
Courtright and Colbert (2011, p. 255) urged researchers to examine the "differential effects of transformational leadership on performance across levels of analysis should ideally be examined using the same sample following multilevel analysis principles (Kozlowski \& Klein, 2000) to ensure that differences in effect sizes across levels of analysis are attributable to differences in levels of analysis alone".

Based on previous research, we expect that:

Hypothesis 2: Shared perceptions of transformational leadership at T2 have a significant cross-level effect on individual self-efficacy at T3, above and beyond previous levels of self-efficacy at $\mathrm{T} 2$ and $\mathrm{T} 1$.

\section{Method}

\section{Sample and Procedure}

A three-wave longitudinal laboratory study was carried out with 481 participants randomly distributed in 118 small groups and involved in three group tasks. Participants were recruited via a website the research group created for this purpose, as well as through ads posted on notice sheets around the college and in the city where the university is located. Participation in the study was voluntary. Participants were informed that the purpose of this study was to know more about how groups work in the context of creative tasks. For the purposes of the study, each group had a leader. These leaders (who were part of each group) were assigned using the same criterion for all the groups, i.e., status depending on age. The oldest member (highest status) of each group was designated as the leader at the beginning of the study. Before beginning the tasks, all the groups received the same instructions for the tasks and the leader's role.

Participants were randomly assigned to each group. To guarantee cooperation on the three tasks and avoid dropouts, members received a monetary reward (20€) for their participation in the study. 
Because the measurement referent for two variables (i.e. group efficacy beliefs and perception of transformational leadership) is the group, agreement indices were performed in order that all the groups shared similar perceptions of the study variables. Six groups with low agreement were excluded from the beginning. So sum up, 456 individuals nested in 112 groups (ranging from four to six members each) are the final participants in the study.

The final sample was a heterogeneous mixed sample consisting of $66 \%$ females, with an average age of 22.5 years. They were university students (80\%) from different degree programmes (Law, Design, Engineering, Languages, Economics, Chemistry, Psychology, Business Management, Teaching and Educational Sciences), full-time workers (11.6\%) representing different occupations, and the unemployed (8.4\%). Participants were allocated to one of the 112 groups in such a way as to ensure that the groups have similar size (i.e. ranging from four to six) and diversity (i.e. similar combinations of students, employed/unemployed people).

Groups were working together during the three laboratory occasions, one time per week in three consecutive weeks. Moreover, each group worked on three creativity tasks (one different creative task per week) in order to avoid learning effects, (Ziessler \& Nattkemper, 2001). Tasks were not complex and involved a unified creative project for two weeks with three face-to-face meetings among the group members. These three specific tasks, as well as the need to achieve a final group product, were chosen to promote important social interactions among group members, group decisions, feelings of efficacy (or not) during the three specific tasks, and the opportunity for leaders to interact with group members. Past research has used creative tasks that were accomplished in three similar time periods (Peñalver et al., 2018; Rodríguez-Sánchez, et al., 2017; Salanova, et al., 2003). At time 1 (T1), groups had to (imaginatively) work for 
a toy company. During each of the three sessions, participants would perform a creative task for 45 minutes. In the first session (T1), they worked on an idea generation task (i.e., a creative slogan). Next lab session (T2), they worked on another creative task, which was to develop a toy prototype composed of recyclable materials. One week later (T3), they designed a poster to market this toy. Upon completing each task, participants, they completed a questionnaire.

\section{Measures}

Transformational Leadership was assessed by the validated Transformational Leadership Scale (Rafferty \& Griffin, 2004), with five dimensions. Vision (three items, e.g. "As a leader, I am perfectly aware of the group's objectives"); Inspirational communication (three items, e.g. "As a leader, I say positive things about the group"); Intellectual stimulation (three items, e.g. "As a leader, I have ideas that stimulate group members to think about questions they had never thought about before"); Support (three items, e.g. "As a leader, I think about the personal needs of the group members"); and Personal recognition (three items, e.g. "As a leader, I congratulate group members when they do an excellent job"). Items were answered on a 7-point Likert-scale ranging from 0 (never) to 6 (always). Group members had to assess their leader's transformational style, and so the referent was the leader (level 2). We used transformational leadership at level II because it included the aggregated scores of all the members of each group related to their individual perceptions of each dimension of transformational leadership. We used a single scale of transformational leadership, and not its highly intercorrelated sub-components, as recommended by Bass (1999).

Collective efficacy was assessed by a scale composed of 4 items, following Bandura's guidelines (validated by Salanova et al., 2003), and adapted to creative tasks in the same way as the self-efficacy scale. Thus, the collective efficacy scale is specific 
rather than general, i.e., creative collective efficacy. An example of an item is "My group can carry out this creative task despite not being familiar with this kind of task". Items were answered on a 7-point Likert-scale ranging from 0 (never) to 6 (always). Group members had to evaluate their group's perception of collective efficacy, so that the referent was the group and not the individual. Hence, collective efficacy was measured at the group level (level 2).

Individual self-efficacy was assessed by a scale composed of 4 items, following Bandura's ideas (validated in Salanova et al., 2003), but using "I" instead of "We" in order to evaluate "individual" self-efficacy. Thus, the self-efficacy scale is specific rather than general, i.e., creative self-efficacy. An example of an item is "I can carry out this creative task even though I am not familiar with this kind of task". Items were answered on a 7-point Likert-scale ranging from 0 (never) to 6 (always). Each member of the group had to evaluate his/her own self-efficacy belief, and so the referent is the individual (level 1).

We use age, gender, and previous levels of individual self-efficacy as control variables in our research model because previous research is inconclusive about selfefficacy differences in different settings. Some studies have shown age (Bausch, Michel, \& Sonntag, 2014; Fukudome, \& Morinaga, 2018; Grau, Salanova, \& Peiró, 2001; Schweder, 2018) and gender differences (Beauregard, 2012; Huang, 2013; Huszczo, \& Endres, 2017; Ye, Posada, \& Liu, 2018), whereas other studies failed to find differences (Beas, \& Salanova, 2006; Salanova, Peiró, \& Schaufeli, 2002). We also included baseline levels of individual self-efficacy in T1 in order to control previous variance in this variable.

\section{Data analysis}


First, we computed descriptive analyses with the study variables. Furthermore, to assess the convergent validity of the scales, the composite reliability (CR) level was calculated (Chin, 1998). According to Nunnally (1967), CR should be greater than 0.7 . Moreover, discriminant validity was checked by using the Average Variance Extracted (AVE) (Fornell \& Larcker, 1981), being acceptable when it is greater than 0.5 (Chin, 1998). Second, because some of the study variables are collective, to test whether the group members showed sufficient agreement on the variables (i.e. group efficacy beliefs and perceived transformational leadership), we examined several indicators of withingroup consensus, such as the $r_{\mathrm{wg}}$ index of within-group agreement (James, Demaree, \& Wolf, 1993) and the intra-class correlation coefficients ICC(1) (Bliese, 2000; Bryk \& Raudenbush, 1992). Values higher than .12 for ICC1 indicate an adequate level of within-unit agreement (James et al., 1984). ICC2 values greater than .60 were recommended by Glick (1985). $\mathrm{r}_{\mathrm{wg}(\mathrm{j})}$ cut-off point values ranging between .51 and .70 have moderate, and values between .71 to .90 strong agreements (LeBreton \& Senter, 2007). So far, these indices support the individual responses aggregation at the next (group) level.

Third, our data are hierarchical because participants were nested within groups and within leaders. Hence, we used hierarchical linear modelling (HLM; Hox, 2002) to test the hypotheses. We can add multilevel predictors and improve the model, considering that a previous model could be tested taking into account a likelihood ratio statistic (Hox, 2002). In our study, we controlled for the effects of previous self-efficacy (T1 as baseline and T2) to investigate the influence of T2 collective efficacy and T2 transformational leadership on T3 self-efficacy. To compute multilevel analyses, we used MlwiN 2.02 software (Rashbash, Browne, Healy, Cameron, \& Charlton, 2005). 
Finally, all the variables, except the dummy variables (gender and age), were grandmean centred for the model estimation (Bryk \& Raudenbush, 1992).

\section{Results}

\section{Descriptive and aggregation analyses}

Table 1 presents means, standard deviations, bivariate correlations, internal consistencies (Cronbach's alpha), and convergent (CR) and discriminant validity (AVE) for all the variables in the study. All the Cronbach's alpha coefficients met the criterion value of .70 (ranging from .83 to .97), and the variables met the criterion for convergent and discriminant validity (CR values grater than 0.7 and AVE values greater than 0.5$)$. As expected, all the study variables were positively and significantly related to selfefficacy at T3 and to the rest of our study variables. Based on Cohen's (1988) convention to interpret effect sizes, all the variables related to self-efficacy at T3 had a moderate to strong correlation. Finally, mean values (and standard deviations) of the collective measures were 4.60 (0.60) for group efficacy beliefs and $4.42(0.75)$ for shared transformational leadership.

\section{PLEASE INSERT TABLE 1 ABOUT HERE}

Regarding the aggregation of our study variables, the ICC1 value for T2 collective efficacy was .24; the T2 transformational leadership ICC1 value was: .38; the ICC2 value for T2 collective efficacy was .58; and for T2 transformational leadership, the value was .71 . The mean $r_{\mathrm{wg}(\mathrm{j})}$ value for $\mathrm{T} 2$ collective efficacy at the group level was $.81(\mathrm{SD}=.11)$, and for $\mathrm{T} 2$ transformational leadership, it was .73 $(\mathrm{SD}=.13)$. This means there is strong agreement on both variables, according to the cut-off points of LeBreton and Senter (2007). Hence, given the satisfactory ICC1, ICC2 (except T2 collective efficacy, for which the ICC2 was .58, but very close to .60), and $r_{w g(j)}$ values, we aggregated at the group level the variables of the present study. 


\section{Hypothesis testing}

We calculated the intraclass correlation for the study variables to estimate the proportion of variance explained at each level studied (Hox, 2002). The results showed that $71 \%$ of the variance in $\mathrm{T} 3$ self-efficacy is explained by variables from the individual, and $29 \%$ from the group levels. These results suggests that a significant proportion of T3 self-efficacy variance may be explained by group-level variables (group efficacy beliefs and shared transformational leadership).

Then we tested 3 nested models, i.e., Model 0 intercept-only; Model 1, in which we added the variables at the first level, including the control variables age, gender, T1 self-efficacy, and T2 self-efficacy; and Model 2, with second level variables (i.e, T2 group efficacy beliefs and T2 shared transformational leadership). Table 2 presents unstandardized estimates, standard errors, $t$ values and the deviance $(-2 * \log )$.

\section{PLEASE INSERT TABLE 2 ABOUT HERE}

Results showed that Model 1 is better than Model 0. Variables at the individual level (T1 and T2 self-efficacy) are significantly related to T3 self-efficacy, and gender and age had no significant effect on T3 self-efficacy. In Model 2, we tested predictor variables at the group level, and T2 group efficacy beliefs and T2 shared transformational leadership were found to exert a significant effect on T3 self-efficacy. According the deviance levels, there is a significant improvement over Model 1. Thus, Model 2 got the better fit, showing significant effects of both individual (i.e. T1 and T2 self-efficacy) and group variables (i.e., T2 group efficacy beliefs, T2 shared transformational leadership) on the development of future self-efficacy (at T3). In other words, perceived collective efficacy of the group and perceived transformational leadership at T2 predicted participants' self-efficacy at T3, and these relationships were 
significant beyond previous levels (T1 and T2) of individual self-efficacy (thus confirming our hypotheses) (see the multilevel model in Figure 1).

\section{PLEASE INSERT FIGURE 1 ABOUT HERE}

\section{Discussion}

The present study builds on our understanding of the role of "collective" sources of individual self-efficacy over time, i.e. shared group perceptions of transformational leadership and group efficacy beliefs, extending the Social Cognitive Theory (Bandura, 1998, 2001, 2012). The study expands our understanding about what are relevant indicators that explain the development of individual self-efficacy over time, providing support for the idea that collective efficacy and leadership together play a relevant role as group-level drivers of the development of individual self-efficacy over time. The results simultaneously show the effects of collective psychosocial mechanisms on selfefficacy over time.

The study demonstrates a comprehensive multilevel and longitudinal model of the interplay between collective (group) antecedents or drivers of individual selfefficacy involving cross-level links between the group and individual levels of analysis. Previous research has shown that sources of self-efficacy, such as enactive mastery, social persuasion, positive emotions and vicarious experiences are able to influence efficacy beliefs (Bandura, 2001, 2012), but our findings extend previous literature on antecedents of self-efficacy from a multilevel perspective, by considering the dynamics of changes in self-efficacy over time. In this regard, the main study contributions reside in empirically testing the idea that the group may be responsible for building selfefficacy. In other words, working in an efficacious group helps to build the future selfefficacy of its members. Previous research has focused on individual effects of selfefficacy (Bandura, 2012; Buric \& Macuka, 2018; Guarnaccia, et al., 2018; Lisbona et 
al., 2018; Peterson et al., 2011; Salanova, Llorens, \& Schaufeli, 2011; Schneider \& Preckel, 2017; Stajkovic, Lee, \& Nyberg, 2009; Talsma, Schüz, \& Norris, 2019) or collective predictors of collective efficacy beliefs (Alavi, \& McCormick, 2018; Gully, Incalcaterra, Joshi, \& Beaubien, 2002; Nielsen \& Daniels, 2012; Salanova, et al., 2003; Salanova, Llorens, \& Schaufeli, 2011; Stajkovic, Lee, \& Nyberg, 2009). Our findings confirm that individual self-efficacy can be explained by group variables (perhaps through emotional contagion) such as shared collective efficacy beliefs and shared perceptions of positive leaders. Our results support the Tee (2015) study, which stressed that emotional contagion processes are developed not only bottom-up, but also topdown where leadership processes are relevant as well. Future studies could test these emotional mechanisms more in-depth.

The results of this study yield a number of theoretical implications. The finding that group efficacy beliefs are a significant cross-level predictor of individual selfefficacy over time supports the importance of the group's beliefs about their efficacy because a group is a driver of each individual's efficacy beliefs over time. According to Bandura, emotional expression is a very valuable source of self-efficacy. Future research should test the mediating role of positive emotions at the group and individual levels of analysis as a psychological mechanism to explain why group efficacy beliefs can influence individual self-efficacy over time.

Another interesting theoretical implication has to do with the way positive leaders encourage collaborators' advancement and strength, in a way of expanding their capabilities and inspiration (Kark, Shamir, \& Chen, 2003). Transformational leaders use their inspirational motivation influencing collaborators' self-efficacy by setting clear goals for their followers and communicating a positive better future. In addition, these leaders could improve their collaborators' self-esteem because they use an 
individualized consideration of each one. In our study, we found that transformational leaders increased individual self-efficacy over time, as these leaders functioned as role models and applied verbal persuasion strategies through individualized consideration and inspirational motivation (Felfe \& Heinitz, 2010).

Prochazka, Gilova, and Vaculik (2017) suggested that factors such as feedback from customers and colleagues, and work performance could affect self-efficacy. In our study, we showed that there are other drivers of individual self-efficacy apart from transformational leadership, such as group collective efficacy beliefs in combination with baseline levels of previous self-efficacy levels.

Our findings have important practical implications, they suggest managers need to be made aware of how they influence others' efficacy beliefs over time. Idealized influence may be a mechanism that leads group members to feel more efficacious as employees of a company. Through intellectual stimulation, transformational leaders motivate followers to achieve new inspiring goals at work in the future. In fact, previous research has established a link between self-efficacy and future job performance (Lisbona et al., 2018; Peterson et al., 2011; Schneider \& Preckel, 2017; Stajkovic, Lee, \& Nyberg, 2009; Talsma, Schüz, \& Norris, 2019). Therefore, it is important for companies to understand the drivers of self-efficacy in order to enhance employees' self-efficacy beliefs and improve their performance. Our findings highlight the importance of developing individual self-efficacy as a powerful psychological resource to achieve goals at work and improve performance.

We strongly recommend that leaders develop a transformational style in order to enhance the individual self-efficacy of their followers. Specific healthy practices, such as open dialogue with followers through an empathic attitude, group training showing leaders how to engage in these positive behaviours, individual interactions 
with followers with a compassionate attitude encouraging leaders to enact positive behaviours with their groups, and getting feedback from group members, may help managers adopt a transformational style with positive benefits for leaders, followers, and companies.

In addition, the positive cross-level influence of group collective efficacy beliefs on individual efficacy beliefs over time is an important finding in SCT because it seems that some of the variance in individual self-efficacy is explained by more collective (group) levels of shared efficacy beliefs about their own group.

Organizational practices oriented towards building a sense of "group identity" and collective efficacy seem to be important to enhance individual perceptions of selfefficacy over time.

This study has provided some new insights into collective drivers of individual self-efficacy over time, however it has some limitations. We included a heterogeneous mixed sample of students, workers, and unemployed people, which limits generalizability to specific companies or occupations. Another limitation is the use of self-report measures. However, in our study we used psychological constructs such as "beliefs", and in these cases it is not appropriated to use objective data. In that cases, we common-method bias could treat to our results, however, we followed Podsakoff, MacKenzie and Podsakoff (2012) recommendations in constructing our survey in order to minimize bias. Furthermore, we did not observe high correlations among the study variables, and so common method variance is not a threat to our data (Spector, 2006). Finally, using three creative tasks, we achieved the study objectives; however, our results could be limited to creative tasks in groups, and replication of these findings using other tasks should be carried out.

\section{Conclusion}


To sum up, this study furthers our understanding of the way group (collective) efficacy and shared perceptions of transformational leadership are linked to members group' self-efficacy over time and in a group context. In addition, we showed crosslevel drivers of individual self-efficacy, and so our results add to SCT by enhancing our understanding of the dynamic nature of the way shared group cognitions of collective efficacy and leadership style are linked to self-efficacy over time. We believe our results are a first step towards answering a key question in self-efficacy research, i.e. how collective processes simultaneously influence individual self-efficacy over time. 


\section{Notes}

\section{Compliance with Ethical Standards}

\section{Conflicts of Interest}

The corresponding author, and coauthors, states that there are no conflicts of interest.

\section{Informed Consent}

We obtained the informed consent from all participants in the study.

\section{Ethical Approval}

The procedures performed in our study involved human participants and they agreed the ethical standards of the institutional research committee, and also with the 1964 Helsinki declaration and its later amendments or comparable ethical standards. 


\section{References}

Afsar, B., \& Masood, M. (2018). Transformational Leadership, Creative Self-Efficacy, Trust in Supervisor, Uncertainty Avoidance, and Innovative Work Behavior of Nurses. The Journal of Applied Behavioral Science, 54(1), 36-

61. https://doi.org/10.1177/0021886317711891

Alavi, S.B. \& McCormick, J. (2018). Why do I think my team is capable? A study of some antecedents of team members' personal collective efficacy beliefs. Educational Psychology, (38)9, 1147-1162. https://doi.org/10.1080/01443410.2018.1500680

Bandura A. (1997). Self-efficacy: The exercise of control. Freeman, New York.

Bandura, A. (2001). Social cognitive theory: An agentic perspective. Annual Review of Psychology, 52, 1-26. https://doi.org/10.1146/annurev.psych.52.1.1

Bandura, A. (2006). Guide for constructing self-efficacy scales. In F. Pajares \& T. Urdan (Eds.). Self-efficacy beliefs of adolescents, (Vol. 5., pp. 307-337). Greenwich, CT: Information Age Publishing.

Bandura, A. (2012). On the Functional Properties of Perceived Self-Efficacy Revisited. Journal of Management, 38(1), 9-44. https://doi.org/10.1177/0149206311410606

Barsade, S. G., \& Knight, A. P. (2015). Group Affect. Annual Review of Organizational Psychology and Organizational Behavior, 2(1), 21-46. doi:10.1146/annurevorgpsych-032414-111316 
Barsade, S.G. (2002). The ripple effect: Emotional contagion and its influence on group behavior. Administrative Science Quarterly, 47(4), 644-675. https://doi.org/10.2307/3094912

Bartel, C.A., \& Saavedra, R. (2000). The collective construction of work group moods. Administrative Science Quarterly, 45(2), 197-231. https://doi.org/10.2307/2667070

Bass, B.M. (1990). From transactional to transformational leadership: Learning to share the vision. Organizational Dynamics, 18(3), 19-32. https://doi.org/10.1016/0090-2616(90)90061-S

Bass, B.M. (1999). Two decades of research and development in transformational leadership. European Journal of Work and Organizational Psychology, 8(1), 932. https://doi.org/10.1080/135943299398410

Bausch, S., Michel, A. \& Sonntag, K. (2014). How gender influences the effect of age on self-efficacy and training success. International Journal of Training and Development, 18(3), 171-187. https://doi.org/10.1111/ijtd.12027

Beas, M.I., \& Salanova, M. (2006). Self-efficacy Beliefs, Computer Training and Psychological Well-Being among Information and Communication Technology Workers. Computers in Human Behavior, 22(6), 1043-1058. https://doi.org/10.1016/j.chb.2004.03.027

Beauregard, T.A. (2012). Perfectionism, self-efficacy and OCB: the moderating role of gender. Personnel Review, 41(5), 590-

608. https://doi.org/10.1108/00483481211249120

Bliese, P.D. (2000). Within-group agreement, non-independence, and reliability: Implications for data aggregation and analyses. In K. J. Klein \& S.W. 
Kozlowski (Eds.), Multilevel theory, research, and methods in organizations:

Foundations, extensions, and new directions (pp.349-381). San Francisco: Jossey-Bass.

Bryk, A., \& Raudenbush, S. (1992). Hierarchical linear models: Applications and data analysis methods. Thousand Oaks, CA, US: Sage Publications, Inc.

Buric, I., \& Macuka, I. (2018). Self-efficacy, emotions and work engagement among teachers: A two wave cross-lagged analysis. Journal of Happiness Studies, 19(7), 1917-1933. https://doi.org/10.1007/s10902-017-9903-9

Chi, N.-W., Chung, Y.-Y., \& Tsai, W.-C. (2011). How Do Happy Leaders Enhance Team Success? The Mediating Roles of Transformational Leadership, Group Affective Tone, and Team Processes. Journal of Applied Social Psychology, 41(6), 1421-1454. https://doi.org/10.1111/j.1559-1816.2011.00767.x

Chin, W. W. (1998). The partial least squares approach to structural equation modeling. Modern methods for business research, 295(2), 295-336.

Cohen, S. (1988). Perceived stress in a probability sample of the United States. In S. Spacapan \& S. Oskamp (Eds.), The Claremont Symposium on Applied Social Psychology. The social psychology of health (pp. 31-67). Thousand Oaks, CA, US: Sage Publications, Inc.

Dvir, T., Eden, D., Avolio, B.J., \& Shamir, B. (2002). Impact of transformational leadership on follower development and performance: A field experiment. Academy of Management Journal, 45(4), 735-744. https://doi.org/10.5465/3069307 
Eden, D. (1990). Pygmalion in Management: Productivity as a self-fulfilling prophecy. Lexington: D.C. Health.

Felfe, J., \& Heinitz, K. (2010). The impact of consensus and agreement of leadership perceptions on commitment, Organizational Citizenship Behaviour, and customer satisfaction. European Journal of Work and Organizational Psychology, 19(3), 279-303. http://dx.doi.org/10.1080/13594320802708070

Fornell, C. \& Larcker, D. F. (1981). Evaluating Structural Equation Models with Unobservable Variables and Measurement Error. Journal of Marketing Research, 18(1), 39-50. https://doi.org/10.1177/002224378101800104

Fukudome, K., \& Morinaga, Y. (2018). Age-related differences in the positive and negative method factors on self-evaluation scales: The Rosenberg Self-Esteem Scale and the Self-Efficacy Scale. The Japanese Journal of Educational Psychology, 66(3), 212-224. http://dx.doi.org/10.5926/jjep.66.212

Grau, R., Salanova, M., \& Peiró, J. M. (2001). Moderator effects of self-efficacy on occupational stress. Psychology in Spain, 5(1), 63-74.

Guarnaccia, C.; Scrima, F.; Civilleri, A.; \& Salerno, L. (2018). The role of occupational self-efficacy in mediating the effect of job insecurity on work engagement, satisfaction and general health. Current Psychology, 37(3), 488-497. https://doi.org/10.1007/s12144-016-9525-0

Gully, S.M., Incalcaterra, K.A., Joshi, A., \& Beaubien, J.M. (2002). A meta-analysis of group efficacy, potency, and performance: Interdependence and level of analysis as moderators of observed relationships. Journal of Applied Psychology, 87(5), 819-832. DOI: 10.1037//0021-9010.87.5.819

Hatfield, E., Cacioppo, J.T., \& Rapson, R.L. (1993). Emotional contagion. Cambridge: Cambridge University Press. 
Hirschfeld, R. R., \& Bernerth, J. B. (2008). Mental efficacy and physical efficacy at the team level:Inputs and outcomes among newly formed action teams. Journal of Applied Psychology, 93, 1429-1437. http://psycnet.apa.org/doi/10.1037/a0012574

Hofmann, D.A., Griffin, M.A., \& Gavin, M.B. (2000). The application of hierarchical linear modeling to organizational research. In K. Klein \& S. Kozlowski (Eds.), Multilevel theory, research, and methods in organizations: Foundations, extensions, and new directions (pp. 467-511). San Francisco: Jossey-Bass.

Hogg, M.A., Martin, R., Epitropaki, O., Mankad, A., Svensson, A., \& Weeden, K. (2005). Effective leadership in salient group: revisiting leader-member exchange theory from the perspective of the social identity theory of leadership. Personality and Social Psychology Bulletin, 31(7), 991-1004. https://doi.org/10.1177/0146167204273098

Hox, J.J. (2002). Multilevel analysis techniques and applications. Manwah, NJ: Lawrence Erlbaum Associates.

Huang, C. (2013). Gender differences in academic self-efficacy: a meta-analysis. European Journal of Psychology of Education, 28(1), 1-35. https://doi.org/10.1007/s10212-011-0097-y

Huszczo, G. \& Endres, M. L. (2017). Gender differences in the importance of personality traits in predicting leadership self-efficacy. International Journal of Training and Development, 21(4), 304-317. https://doi.org/10.1111/ijtd.12113

James, L.R., Demaree, R.G., \& Wolf, G. (1984). Estimating within-group interrater reliability with and without response bias. Journal of Applied Psychology, 69(1), 85-98. http://dx.doi.org/10.1037/0021-9010.69.1.85 
Kark, R., Shamir, B., \& Chen, G. (2003). The two faces of transformational leadership: Empowerment and dependency. Journal of Applied Psychology, 88(2), 246255. http://dx.doi.org/10.1037/0021-9010.88.2.246

Kozlowski, S.W.J. \& Klein, K. (2000). A multilevel approach to theory and research on organizations: Contextual, temporal, and emergent processes. In K.J. Klein \& S.W.J. Kozlowski (Eds.), Multilevel theory, research, and methods in organizations (pp.3-90). San Francisco, CA: Jossey-Bass.

LeBreton, J.M. \& Senter, J.L. (2007). Answers to 20 questions about interrater reliability and interrater agreement. Organizational Research Methods, 11(4), 815-852. https://doi.org/10.1177/1094428106296642

Legood, A., Thomas, G. \& Sacramento, C. (2016). Leader trustworthy behavior and organizational trust: the role of the immediate manager for cultivating trust. Journal of Applied Social Psychology, 46(12), 673-686. https://doi.org/10.1111/jasp.12394

Lisbona, A., Palací, F., Salanova, M. \& Frese, M. (2018). The effects of work engagement and self-efficacy on personal initiative and performance. Psicothema, 30(1), 89-96. https://www.redalyc.org/articulo.oa?id=727/72754594014

Liu, J., Siu, O., \& Shi, K. (2010). Transformational leadership and employee wellbeing: The mediating role of trust in the leader and self-efficacy. Applied Psychology: An International Review, 59(3), 454-479. https://doi.org/10.1111/j.1464-0597.2009.00407.x

Martínez, I., \& Cifre, E. (2016). Individual and group antecedents of satisfaction: One lab- multilevel study. Anales De PsicologíA / Annals of Psychology, 32(2), 565-570. https://doi.org/10.6018/analesps.32.2.216801 
Nielsen, K. \& Daniels, K. (2012). Does shared and differentiated transformational leadership predict followers' working conditions and well-being? The Leadership Quarterly, 23(3), 383-397. https://doi.org/10.1016/j.leaqua.2011.09.001

Nielsen, K. \& Munir, F. (2009). How do transformational leaders influence followers' affective well-being? Exploring the mediating role of self-efficacy. Work \& Stress, 23(4), 313-329. DOI: 10.1080/02678370903385106

Nunnally, J. C. (1967). Psychometric theory. New York: McGraw-Hill.

Peñalver, J., Salanova, M., Martínez, I. M., \& Schaufeli, W. B. (2019). Happyproductive groups: How positive affect links to performance through social resources. The Journal of Positive Psychology, 14(3), 377-

392. https://doi.org/10.1080/17439760.2017.1402076

Peterson, S. J., Luthans, F., Avolio, B. J., Walumbwa, F. O. \& Zhang, Z. (2011). Psychological capital and employee performance: A latent growth modeling approach. Personnel Psychology, 64(2), 427-50. https://doi.org/10.1111/j.1744-6570.2011.01215.x

Pillai, R., \& Williams, E.A. (2004). Transformational leadership, self-efficacy, group cohesiveness, commitment, and performance. Journal of Organizational Change Management, 17(2), 144-159. https://doi.org/10.1108/09534810410530584

Podsakoff, P.M., MacKenzie, S.B., \& Podsakoff, N.P. (2012). Sources of method bias in social science research and recommendations on how to control it. Annual Review of Psychology, 63, 539-569. https://doi.org/10.1146/annurev-psych$\underline{120710-100452}$ 
Podsakoff, P.M., MacKenzie, S.B., Moorman, R.H., \& Fetter, R. (1990).

Transformational leader behaviors and their effects on followers' trust in leader, satisfaction, and organizational citizenship behaviors. The Leadership

Quarterly, 1(2), 107-142. https://doi.org/10.1016/1048-9843(90)90009-7

Prochazka, J., Gilova, H. \& Vaculik, M. (2017). The Relationship Between

Transformational Leadership and Engagement: Self-Efficacy as a Mediator.

Journal of Leadership Studies, 11(2), 22-33. https://doi.org/10.1002/j1s.21518

Rafferty, A.E. \& Griffin, M.A. (2004). Dimensions of transformational leadership:

Conceptual and empirical extensions. The Leadership Quarterly, 15(3), 329-

354. https://doi.org/10.1016/j.leaqua.2004.02.009

Rashbash, J., Browne, W., Healy, M., Cameron, B., \& Charlton, C. (2005). MlwiN

(Version 2.02): Interactive software for multilevel analysis. Multilevel Models Project, Institute of Education, University of London: London.

Rodríguez-Sánchez, A. M., Devloo, T., Rico, R., Salanova, M., \& Anseel, F. (2017). What makes creative teams tick? Cohesion, engagement, and performance across creativity tasks: A three-wave study. Group \& Organization Management, 42(4), 521-547. https://doi.org/10.1177/1059601116636476

Salanova, M., Llorens, S. \& Schaufeli, W.B. (2011). Yes, I Can, I Feel Good \& I Just Do It! On Gain Cycles and Spirals of Efficacy Beliefs, Affect, and Engagement. Applied Psychology: An International Review, 60(2), 255-285. https://doi.org/10.1111/j.1464-0597.2010.00435.x

Salanova M, Llorens S, Cifre E, Martínez, I.M. \& Schaufeli, W.B. (2003). Perceived collective efficacy, subjective well-being and task performance among electronic work groups: An experimental study. Small Group Research 34(1), 43-73. https://doi.org/10.1177/1046496402239577 
Salanova, M., Lorente, L., Chambel, M.J. \& Martínez, I.M. (2011). Linking transformational leadership to nurses' extra-role performance: the mediating role of self-efficacy and work engagement. Journal of Advanced Nursing, 67(10), 2256-2266. https://doi.org/10.1111/j.1365-2648.2011.05652.x

Salanova, M., Peiró, J.M., \& Schaufeli, W.B. (2002). Self-efficacy Specificity and Burnout among Information Technology Workers: An extension of the Job Demands-Control Model. European Journal on Work and Organizational Psychology, 11, 1-25. https://doi.org/10.1080/13594320143000735

Schneider, M. \& Preckel, F. (2017). Variables associated with achievement in higher education: A systematic review of meta-analyses. Psychological Bulletin, 143(6), 565-600. http://dx.doi.org/10.1037/bul0000098

Seong, J. Y., \& Choi, J. N. (2014). Effects of Group-Level Fit on Group Conflict and Performance. Group \& Organization Management, 39(2), 190-212. https://doi.org/10.1177/1059601113517138

Sivanathan, N., Arnold, K.A., Turner, N., \& Barling, J. (2004). Leading well: Transformational leadership and well-being. In A. Linley \& S. Joseph (Eds.), Positive psychology in practice (pp. 241-255). Hoboken, NJ: Wiley.

Spector, P.E. (2006). Method variance in organizational research: Truth or urban legend. Organizational Research Methods, 9(2), 221-232. https://doi.org/10.1177/1094428105284955

Stajkovic, A.D., Lee, D., \& Nyberg, A.J. (2009). Collective efficacy, group potency, and group performance: Meta-analyses of their relationships, and test of a mediation model. Journal of Applied Psychology, 94(3), 814-828. http://dx.doi.org/10.1037/a0015659 
Stetz, T.A., Stetz, M.C., \& Bliese, P.A., (2006). The importance of self-efficacy in the moderating effects of social support on stressor-strain relationships. Work \& Stress, 20(1), 49-59. https://doi.org/10.1080/02678370600624039

Schweder, S. (2018). The role of control strategies, self-efficacy, and learning behavior in self-directed learning. International Journal of School \& Educational Psychology, http://dx.doi.org/10.1080/21683603.2018.1459991

Talsma. K., Schüz, B. \& Norris, K. (2019). Miscalibration of self-efficacy and academic performance: Self-efficacy $\neq$ self-fulfilling prophecy. Learning and Individual Differences, 69, 182-195. https://doi.org/10.1016/j.lindif.2018.11.002

Torrente, P., Salanova, M., \& Llorens, S. (2013). Spreading engagement: On the role of similarity in the positive contagion of teamwork engagement. Journal of Work and Organizational Psychology, 29(3), 153-159. https://doi.org/10.5093/tr2013a21

Tee, E.Y.J. (2015). The emotional link: Leadership and the role of implicit and explicit emotional contagion processes across multiple organizational levels. The Leadership Quarterly, 26(4), 654-670. https://doi.org/10.1016/j.leaqua.2015.05.009

Wallumbwa, F.O., Mayer, D.M., Wang, P., Wang, H., Workman, K \& Christensen, A.L. (2011). Linking ethical leadership to employee performance: The roles of leader-member exchange, self-efficacy, and organizational identification. Organizational Behavior and Human Decision Processes, 115(2), 204-213. https://doi.org/10.1016/j.obhdp.2010.11.002

Wang, G., Oh, I., Courtright, S.H., \& Colbert, A.E. (2011). Transformational leadership and performance across criteria and levels: A Meta-Analytic review of 25 years 
of research. Group \& Organization Management, 36(2), 223-270.

https://doi.org/10.1177/1059601111401017

Yammarino, F.J., Dionne, S.D., Chun, J.U., \& Dansereau, F. (2005). Leadership and levels of analysis: A state-of-the-science review. The Leadership Quarterly, 16(6), 879-919. https://doi.org/10.1016/j.leaqua.2005.09.002

Ye, L.; Posada, A.; \& Liu, Y. (2018). The moderating effects of gender on the relationship between academic stress and academic self-efficacy. International Journal of Stress Management, 25(1), 56-61. http://dx.doi.org/10.1037/str0000089

Zhang, L., Zhang, N., \& Qiu, Y. (2017). Positive group affective tone and employee work engagement: A multilevel investigation. Social Behavior and Personality: An International Journal, 45(11), 1905-1918. doi:10.2224/sbp.6751

Ziessler, M., \& Nattkemper, D. (2001). Learning of event sequences is based on response-effect learning: Further evidence from a serial reaction task. Journal of Experimental Psychology: Learning, Memory, and Cognition, 27(3), 595-613. http://dx.doi.org/10.1037/0278-7393.27.3.595 
Table 1

Means, Standard Deviations, Correlations, Internal consistencies, Composite Reliability (CR) and Average Variance Extracted (AVE)

\begin{tabular}{llccccccccccc}
\hline & Mean & SD & 1 & 2 & 3 & 4 & 5 & CR & AVE \\
\hline 1 & T1 Self-efficacy & 4.29 & .91 & $. .83)$ & $.50^{* * *}$ & $.49^{* * *}$ & $.37^{* * *}$ & $.21^{*}$ & .85 & .58 \\
2 & T2 Self-efficacy & 4.35 & .94 & $.45^{* * *}$ & $(.87)$ & $.74^{* * *}$ & $.87^{* * *}$ & $.35^{* * *}$ & .87 & .62 \\
3 & T3 Self-efficacy & 4.68 & .89 & $.44^{* * *}$ & $.64^{* * *}$ & $(.89)$ & $.69^{* * *}$ & $.46^{* * *}$ & .94 & .66 \\
4 & T2 Group efficacy beliefs & 3.61 & .57 & $.31^{* * *}$ & $.75^{* * *}$ & $.49^{* * *}$ & $(.88)$ & $.48^{* * *}$ & .88 & .64 \\
5 & T2 Shared Transf. Leadership & 4.41 & .73 & $.11^{*}$ & $.21^{* * *}$ & $.31^{* * *}$ & $.25^{* * *}$ & $(.97)$ & .97 & .84
\end{tabular}

Note. Individual-level intercorrelations below the main diagonal $(\mathrm{N}=456)$ and group-level intercorrelations above the main diagonal $(\mathrm{k}=112)$. Alpha coefficients on the diagonal.

$* * * \mathrm{p}<.01, * \mathrm{p}<.05$

According to Cohen's (1988) conventions to interpret effect size: A correlation coefficient of .10 is thought to represent a weak or small association; a correlation coefficient of .30 is considered a moderate correlation; and a correlation coefficient of .50 or larger is thought to represent a strong or large correlation. 


\section{Table 2}

Hierarchical linear models predicting Self-efficacy T3 (level 1 individuals $\mathrm{N}=456$;

level 2 groups $\mathrm{N}=112$ )

\begin{tabular}{lcc}
\hline \multicolumn{1}{c}{ Parameters } & Model 1 & Model 2 \\
\hline & Fixed effects & \\
Intercept & $4.67 * * *(0.16)$ & $4.65^{* * *}(0.15)$ \\
Level 1 (individuals) & $-0.39(0.07)$ & $-0.01(0.07)$ \\
$\quad$ Gender & $0.00(0.01)$ & $0.00(0.01)$ \\
$\quad$ Age & $0.17 * * *(0.04)$ & $0.19^{* * *}(0.04)$ \\
$\quad$ Self-efficacy T1 & $0.49 * * *(0.04)$ & $0.43^{* * *}(0.04)$ \\
$\quad$ Self-efficacy T2 & & $0.20^{*}(0.08)$ \\
Level 2 (groups) & & $0.15^{*}(0.06)$ \\
$\quad$ Group efficacy beliefs T2 & & \\
$\quad$ Shared Trans. Leadership T2 & & .23 \\
& & .56 \\
Level 2 & & 890.71 \\
$\quad \mathrm{R}^{2}$ & .78 & \\
Level 1 & 913.59 & \\
$\mathrm{R}^{2}$ & & \\
$-2 * \log$ likelihood & &
\end{tabular}

Note. Standard errors are in parentheses.

$* \mathrm{p}<.05 . * * * \mathrm{p}<.001$. 
TIME 2

TIME 3

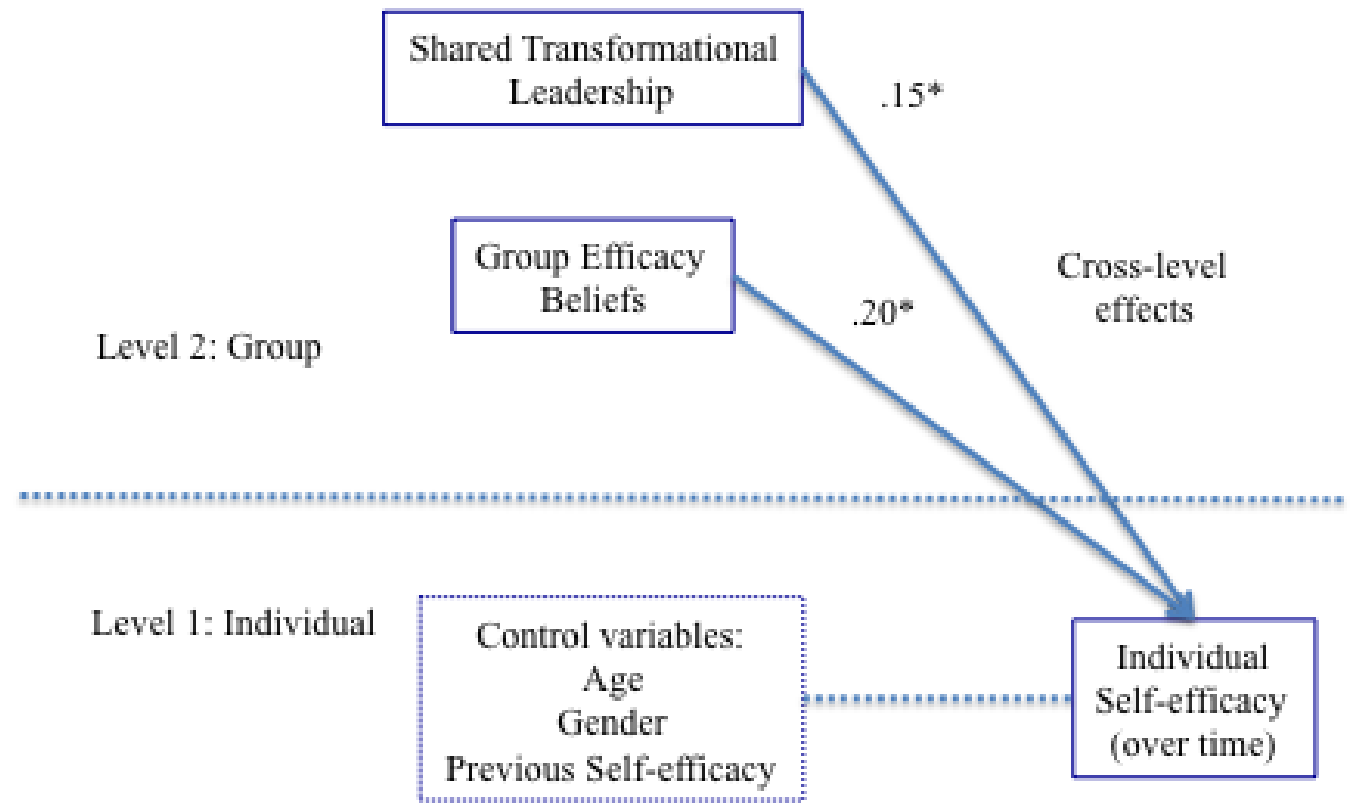

Figure 1. Multilevel Model Results ( $N=112$ groups at level 2, and $N=456$ participants at level 1) 